\title{
BIODEGRADABLE PHOTO-CROSSLINKED ALGINATE NANOFIBRE SCAFFOLDS WITH TUNEABLE PHYSICAL PROPERTIES, CELL ADHESIVITY AND GROWTH FACTOR RELEASE
}

\author{
Sung In Jeong ${ }^{1, \S}$, Oju Jeon ${ }^{1}$, Melissa D. Krebs ${ }^{1}$, Michael C. Hill ${ }^{1}$ and Eben Alsberg ${ }^{1,2, *}$ \\ ${ }^{1}$ Department of Biomedical Engineering, Case Western Reserve University, Cleveland, OH, USA \\ ${ }^{2}$ Department of Orthopaedic Surgery, Case Western Reserve University, Cleveland, OH, USA \\ ${ }^{\S}$ Current address: Advanced Radiation Technology Institute, Korea Atomic Energy Research Institute, \\ 1266 Sinjeong-dong, Jeongeup-si Jeollabuk-do, 580-185, Republic of Korea
}

\begin{abstract}
Nanofibrous scaffolds are of interest in tissue engineering due to their high surface area to volume ratio, interconnected pores, and architectural similarity to the native extracellular matrix. Our laboratory recently developed a biodegradable, photo-crosslinkable alginate biopolymer. Here, we show the capacity of the material to be electrospun into a nanofibrous matrix, and the ability to enhance cell adhesion and proliferation on these matrices by covalent modification with cell adhesion peptides. Additionally, the potential of covalently incorporating heparin into the hydrogels during the photopolymerisation process to sustain the release of a heparin binding growth factor via affinity interactions was demonstrated. Electrospun photocrosslinkable alginate nanofibrous scaffolds endowed with cell adhesion ligands and controlled delivery of growth factors may allow for improved regulation of cell behaviour for regenerative medicine.
\end{abstract}

Keywords: Alginate; electrospinning; photopolymerisation; biomaterials; heparin; tissue engineering.

*Address for correspondence:

Eben Alsberg

Department of Biomedical Engineering and Orthopaedic Surgery

Case Western Reserve University

Wickenden Building, Room 204

10900 Euclid Avenue

Cleveland, OH 44106, USA

Telephone Number: +1 2163686425

FAX Number: +1 2163684969

E-mail: eben.alsberg@case.edu

\section{Introduction}

Wounds occur when the skin is damaged; this can be caused by trauma, burns, diabetic ulcers and surgical procedures. Wound healing is a complex series of events that involves the responses of cells, growth factors and cytokines as well as the extracellular matrix (ECM) (Janis et al., 2010). Conditions such as poor circulation, other illnesses and age can cause wound healing to be delayed or impaired, resulting in chronic non-healing wounds (Wu et al., 2010). Some tissue engineering strategies for wound repair, such as that presented here, seek to provide an artificial dermal layer comprised of a biomaterial scaffold into which dermal fibroblasts can migrate and proliferate. Generally, biomaterials for wound repair should be nontoxic, flexible, durable and non-antigenic during their contact with the tissue.

Additionally, it may be beneficial to deliver bioactive factors from the biomaterial scaffolds to further enhance the tissue regeneration. Several growth factors have been shown to be important in wound healing, including epidermal growth factor, platelet-derived growth factor, transforming growth factor beta and fibroblast growth factor-2 (FGF-2) (Barrientos et al., 2008). FGF-2 is important for cell proliferation and fibroblast infiltration into the wound (Barrientos et al., 2008), and chronic wounds have been found to have decreased levels of FGF-2 (Robson, 1997). Thus, delivering FGF-2 to a wound from a biomaterial serving as temporary dermal matrix may aid in the healing process. This has been examined using FGF-2-laden gelatin microparticles in collagen scaffolds (Park et al., 2009), FGF-2-laden poly(lactic-co-glycolic) acid (PLGA) microparticles in alginate scaffolds (Perets et al., 2003), FGF-2 encapsulated in collagen-heparin hydrogels (Nillesen et al., 2007), poly(ethylene glycol) (PEG) hydrogels (Andreopoulos and Persaud, 2006), heparin-PEG hydrogels (Benoit and Anseth, 2005), polyelectrolyte multi-films comprised of poly(beta-amino esters) and chondroitin sulphate or heparin (Macdonald et al., 2010), silk fibroin scaffolds (Wongpanit et al., 2010), poly(ether)urethane-polydimethylsiloxane and fibrin composite hydrogels (Briganti et al., 2010), chitosan/ hydroxyapatite scaffolds (Tigli et al., 2009), chitosanalginate polyelectrolyte scaffolds (Ho et al., 2009), sulphated alginate hydrogels (Freeman et al., 2008) and PLGA electrospun nanofibres (Sahoo et al., 2010).

Electrospun nanofibres offer an architecture which is a promising option for wound healing matrices; their nanoporous nature may aid in the transport of oxygen to the wound while keeping bacteria out, and bioactive 
(a)

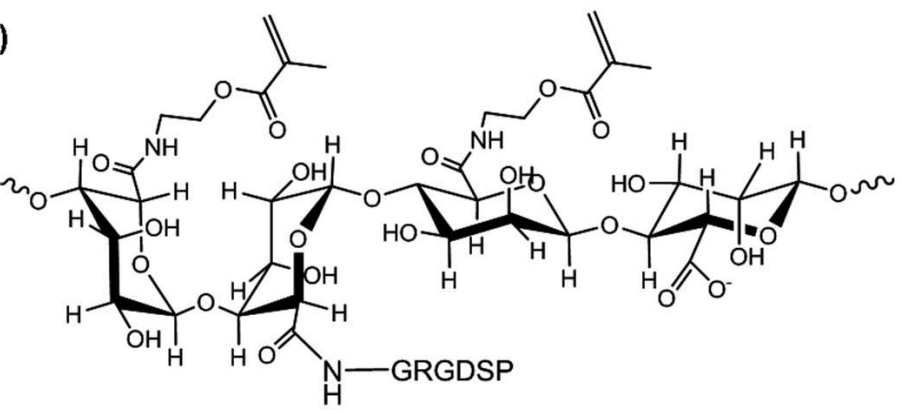

(b)

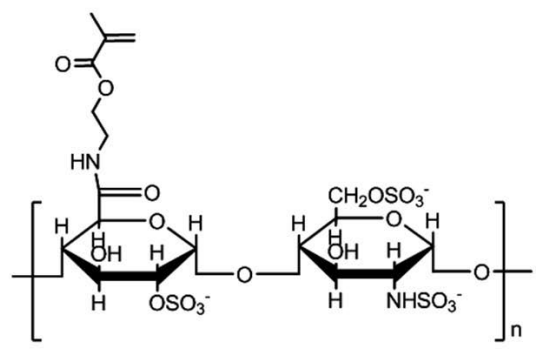

Fig. 1. Chemical structures of (a) methacrylated alginate modified with RGD-containing peptide and (b) methacrylated heparin.

factors can be incorporated into the nanofibres to further promote healing (Zhong et al., 2010). Furthermore, the nanofibrous structure of electrospun scaffolds mimics the structure of the ECM in which cells naturally reside, and has been shown to regulate many cellular processes such as adhesion, spreading, proliferation, alignment and differentiation (Murugan and Ramakrishna, 2006; Pham et al., 2006). In addition, the high surface area to volume ratio maximises cell interactions with these materials, and the subsequent potential for material mediated signalling. Natural materials such as collagen (Powell et al., 2008), chitin (Noh et al., 2006) and gelatin (Powell and Boyce, 2008), as well as synthetic materials such as PEG (Casper et al., 2005) have been examined for use as electrospun scaffolds in wound healing. The use of hydrophilic biomaterials as electrospun nanofibres may be beneficial in retaining an appropriate balance of moisture at the wound to aid in the healing process (Zahedi et al., 2010).

Alginate, a hydrophilic biocompatible polymer derived from seaweed, has been electrospun and ionically crosslinked with calcium to form nanofibrous scaffolds; the cell adhesivity of these scaffolds can be regulated by modifying the alginate backbone with cell adhesive peptides found in natural ECM molecules (Jeong et al., 2010). However, it can be difficult to control the physical properties of ionically crosslinked alginate. Furthermore, although bioactive factors can be incorporated into the alginate fibres, they will rapidly diffuse from the waterswollen network. Our group has recently engineered photo-crosslinkable methacrylated alginate, which provides the capacity to control its physical properties such as degradation rate, swelling, and mechanical properties (Jeon et al., 2009) by varying the degree of alginate methacrylation. Furthermore, the methacrylated alginate, which is initially non-adhesive to cells, can also be covalently modified with cell adhesive peptides to regulate cell behaviours such as cell attachment, spreading and proliferation on or within the matrices (Jeon et al., 2010) and heparin to control and sustain the release of heparinbinding growth factors (Jeon et al., 2011). While many biomaterials have been electrospun to permit investigation of nanofibre structure on cell behaviour, few are at the same time biodegradable with the capacity for both controlled cell adhesion and bioactive factor delivery. Here we report on the ability to electrospin the methacrylated alginate into nanofibres and crosslink the fibres using ultraviolet
(UV) light to form stable nanofibrous scaffolds. The alginate polymer backbone can be covalently modified with cell-adhesive peptides to control cell adhesion (Jeon et al., 2010) (Fig. 1a). Methacrylated heparin (Fig. 1b) can be blended with methacrylated alginate so that upon crosslinking, the alginate scaffold will contain covalently linked heparin to mediate the sustained release of incorporated growth factors (Jeon et al., 2011). Both the peptides and the heparin remain bioactive following the electrospinning process. The resultant nanofibres thus have tuneable physical properties, cell adhesive properties and growth factor release profiles. These electrospun alginate scaffolds have much promise for wound healing and other regenerative medicine applications.

\section{Materials and Methods}

Synthesis of methacrylated alginate, RGD-modified methacrylated alginate and methacrylated heparin Low molecular weight sodium alginate $(37,000 \mathrm{~g} / \mathrm{mol})$ was prepared by irradiating Protanal LF 20/40 (196,000 g/mol, FMC Biopolymer, Philadelphia, PA, USA) at a gamma dose of 5 Mrad. Unmodified methacrylated alginate (UMA) and RGD-modified methacrylated alginate (RMA) were synthesised as described previously, at a theoretical methacrylation of $45 \%$ (25\% actual) (Jeon et al., 2009; Jeon et al., 2010). The methacrylated heparin was prepared as previously described, at a theoretical methacrylation of two carboxylic acid groups per heparin molecule $(\sim 1.4$ actual) (Jeon et al., 2011).

\section{Preparation of methacrylated alginate-PEO nanofibrous scaffolds and photo-crosslinking} UMA and RMA were dissolved in ultrapure deionised water $\left(\mathrm{diH}_{2} \mathrm{O}\right)$ with $0.05 \%(\mathrm{w} / \mathrm{v})$ photoinitiator (Irgacure D-2959, Sigma-Aldrich, St. Louis, MO, USA) at concentrations from 1.0 to $8.0 \%(\mathrm{w} / \mathrm{v})$. Methacrylated heparin was dissolved in this RMA solution at a concentration of $1.0 \%$ (w/v) (HRMA). Poly(ethylene oxide) (PEO, $900 \mathrm{kDa}$, Sigma-Aldrich) was dissolved in $\mathrm{diH}_{2} \mathrm{O}$ with $0.05 \%(\mathrm{w} / \mathrm{v})$ photoinitiator at a concentration of $4.0 \%(\mathrm{w} / \mathrm{v})$. The UMA, RMA, and HRMA were mixed with the PEO at a blending ratio of 50:50 alginate:PEO for 1 day at room temperature using a rotating hybridisation incubator (Model 400; Robbins Scientific, Sunnyvale, CA, USA). 
Table 1. Solution blends used for electrospinning of methacrylated alginate/PEO.

\begin{tabular}{|c|c|c|c|}
\hline Sample code & $\begin{array}{l}\text { Unmodified and } \\
\text { RGD-modified } \\
\text { methacrylated } \\
\text { alginate (wt \%) }\end{array}$ & $\begin{array}{c}\text { PEO } \\
\text { comcentration } \\
(w t \%) \\
\end{array}$ & $\begin{array}{c}\text { Alginate: PEO } \\
\text { vol \% : vol \% } \\
\text { (final wt \% : wt \%) } \\
\end{array}$ \\
\hline UMA14 & 1.0 & 4.0 & $50: 50(0.5: 2.0)$ \\
\hline UMA24 & 2.0 & 4.0 & $50: 50(1.0: 2.0)$ \\
\hline UMA44 & 4.0 & 4.0 & $50: 50(2.0: 2.0)$ \\
\hline UMA84 & 8.0 & 4.0 & $50: 50(4.0: 2.0)$ \\
\hline RMA84 & 8.0 & 4.0 & $50: 50(4.0: 2.0)$ \\
\hline HRMA84 & & 4.0 & $50: 50(4.0: 2.0)$ \\
\hline
\end{tabular}

Fig. 2. Schematic illustration of the sample holder used for uniaxial tensile strength testing of electrospun mats. The resulting gauge length was $5 \mathrm{~mm}$.

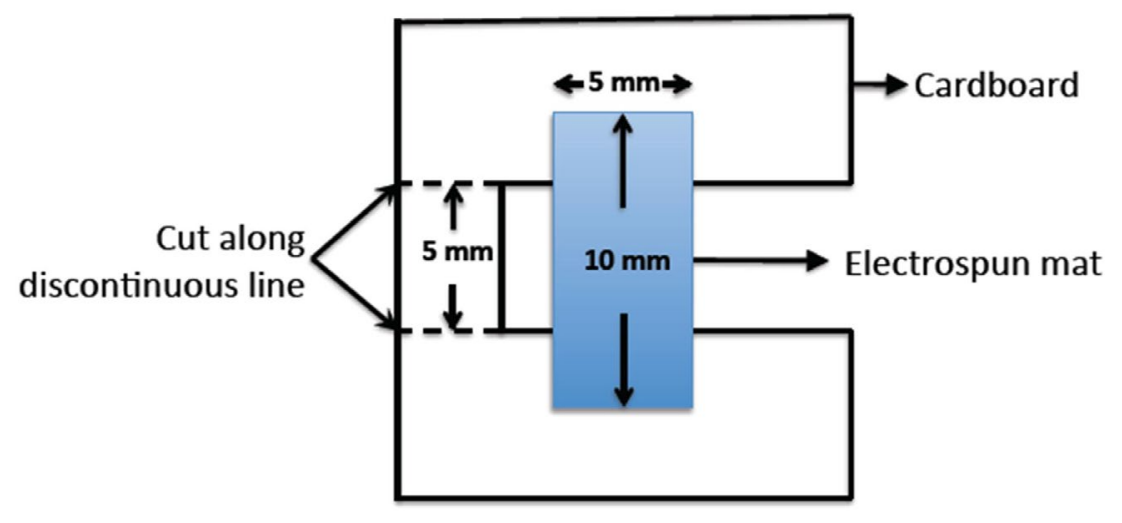

For electrospinning, the blended solutions were loaded in a $5 \mathrm{~mL}$ plastic syringe (Henke Sass Wolf, Tuttlingen, Germany), fitted with a stainless-steel blunt-ended needle (20G, NanoNC, Seoul, Korea). The plastic syringe was placed in an infusion pump (Model 22; Harvard Apparatus Inc., Holliston, MA, USA) and the stainless-steel needle was connected to the positive output of a high-voltage power supply (AU 60PO; Matsusada, Kusatsu, Japan). A custom-made rotating collecting drum (outer diameter: $100 \mathrm{~mm}$, length: $250 \mathrm{~mm}$; NanoNC) was wrapped with aluminium foil and positioned at a fixed distance of $150 \mathrm{~mm}$ from the needle. The applied voltage and flow rate of the infusion pump were fixed to $10.4 \mathrm{kV}$ and $0.01 \mathrm{~mL} /$ min, respectively, and the total spinning time for these scaffolds was $3 \mathrm{~h}$. A list of the solutions examined for electrospinning is presented in Table 1 .

After fabrication, all nanofibres were photo-crosslinked with 365 nm UV light (Model B-100AP, UVP LLC, Upland, CA, USA) at $<1 \mathrm{~mW} / \mathrm{cm}^{2}$ at a distance of $100 \mathrm{~mm}$ from the light for $10 \mathrm{~min}$ and dried overnight at room temperature. The crosslinked nanofibres were then punched into disks (diameter $30 \mathrm{~mm}$ ) using a punch (McMaster Carr, Elmhurst, IL, USA). To extract the PEO from the photo-crosslinked scaffolds, they were incubated in $5 \mathrm{~mL}$ of $\mathrm{diH}_{2} \mathrm{O}$ or Dulbecco's Modified Eagle Medium (DMEM) in 6-well plates at $37^{\circ} \mathrm{C}$ for 5 days with slow shaking. The $\mathrm{diH}_{2} \mathrm{O}$ and DMEM solutions were changed every day. The PEO-extracted scaffolds were rinsed three times with $\mathrm{diH}_{2} \mathrm{O}$, frozen at $-80{ }^{\circ} \mathrm{C}$ overnight, and lyophilised for 3 days.

\section{Morphologies of electrospun photo-crosslinked alginate scaffolds}

The morphologies of the photo-crosslinked alginate nanofibres before and after PEO extraction were examined using a scanning electron microscope (SEM, S-4500, Hitachi, Tokyo, Japan). The samples were coated with gold using a sputter-coater (E-1030, Hitachi) and scanned at an acceleration voltage of $5 \mathrm{kV}$. One representative photomicrograph from each sample was used to measure the diameters of 50 fibres using image analysis software (Image-Pro Plus 6.0, Bethesda, MD, USA).

\section{Mechanical properties of the nanofibrous scaffolds}

The tensile strength, Young's moduli, and elongation at break of the photo-crosslinked MA/PEO nanofibres (UMA84, RMA84, and HRMA84) were determined by performing constant strain rate tensile tests using a Rheometrics Solids Analyser (RSAII, Rheometrics Inc., Piscataway, NJ, USA) equipped with a 10-N load cell. The photo-crosslinked MA/PEO nanofibres were prepared as described above and individual scaffolds were cut from the electrospun mat with dimensions of $10 \times 5 \mathrm{~mm}^{2}(n=5)$ and attached to cardboard using epoxy resin. The sample was centred in a $5 \mathrm{~mm}$ slot in the centre of the cardboard and then glued to standardise the gauge length (Fig. 2). After measuring the sample thickness using a pair of callipers, the cardboard was loaded into the clamps of the Rheometrics device and cut as indicated in Fig. 2. Tensile tests were performed on the scaffolds at room temperature at a cross-head speed of $0.6 \mathrm{~mm} / \mathrm{min}$. The tensile moduli 
of the electrospun nanofibrous scaffolds were determined from the slope of stress $v s$. strain plots, limited to the first linear $2 \%$ strain of the plots.

\section{ATR-FTIR of the nanofibrous scaffolds}

To examine the chemical composition of the photocrosslinked UMA84, RMA84 and HRMA84 nanofibres, attenuated total reflectance-Fourier transform infrared (ATR-FTIR) spectroscopy (Excalibur FTS 3000, Bio-Rad/ Digilab; Bio-Rad, Hercules, CA, USA) was performed. ATR spectra were recorded at 64 scans with a resolution of $40 \mathrm{~cm}^{-1}$ and a scanning range between 2000 and $600 \mathrm{~cm}^{-1}$.

\section{Degradation of the scaffolds}

The degradation of the photo-crosslinked alginate nanofibrous scaffolds was investigated. The photocrosslinked, PEO-extracted, lyophilised UMA84, RMA84 and HRMA84 nanofibrous scaffolds (diameter $20 \mathrm{~mm}, n=2$ per time point) were placed in closed $50 \mathrm{~mL}$ polypropylene conical tubes containing $30 \mathrm{~mL}$ of Dulbecco's Modified Eagle's Medium (DMEM) for 3 weeks at $37^{\circ} \mathrm{C}$. The DMEM was changed every 3 days. Samples were then washed with $\mathrm{diH}_{2} \mathrm{O}$ and lyophilised. At 1,2 , and 3 weeks the samples were imaged using SEM.

\section{Interaction of cells with the photo-crosslinked} alginate nanofibres

Primary human dermal fibroblasts (HDFs, ATCC, Manassas, VA, USA) were maintained in DMEM containing $4.5 \mathrm{~g} / \mathrm{L}$ glucose (DMEM-HG, HyClone, Logan, UT, USA) supplemented with $10 \%$ fetal bovine serum (FBS, HyClone) and $1 \%$ penicillin / streptomycin (P/S, HyClone) at $37{ }^{\circ} \mathrm{C}$ with $5 \% \mathrm{CO}_{2}$ in a humidified environment. Cells were used at passages 4-5.

Photo-crosslinked UMA84, RMA84, and HRMA84 PEO-extracted scaffolds (diameter $20 \mathrm{~mm}, n=5$ ) in 12well tissue culture plates were sterilised by immersion in $70 \%$ ethanol and exposure to UV irradiation for $1 \mathrm{~h}$, washed three times with $\operatorname{diH}_{2} \mathrm{O}$, and seeded with $1 \times 10^{4}$ cells. The scaffolds were stabilised in the bottom of the wells by placing sterilised stainless steel rings $(20 \mathrm{~mm}$ diameter, a generous gift from Dr. Il Keun Kwon, Kyung Hee University, Seoul, Korea) over the scaffolds' outer edge. The cell-laden nanofibres were cultured in $2 \mathrm{~mL}$ media as described above.

To investigate the morphological changes of the cultured cells on the scaffolds, samples were fixed in $3.7 \%$ formaldehyde in phosphate buffered saline (PBS) for $10 \mathrm{~min}$ and then permeabilised in cold cytoskeleton buffer

Fig. 3. Scanning electron micrographs of electrospun unmodified methacrylated alginate (UMA), RGD-modified methacrylated alginate (RMA), as well as heparin and RGD-modified methacrylated alginate (HRMA) nanofibres (prior to PEO extraction) (a-f) before and (g-l) after cross-linking using UV irradiation. Images represent: (a and g) UMA14 (b and h) UMA24 (c and i) UMA44, (d and j) UMA84, (e and k) RMA84, and (f and l) HRA84. Scale bars represent $3 \mu \mathrm{m}$.
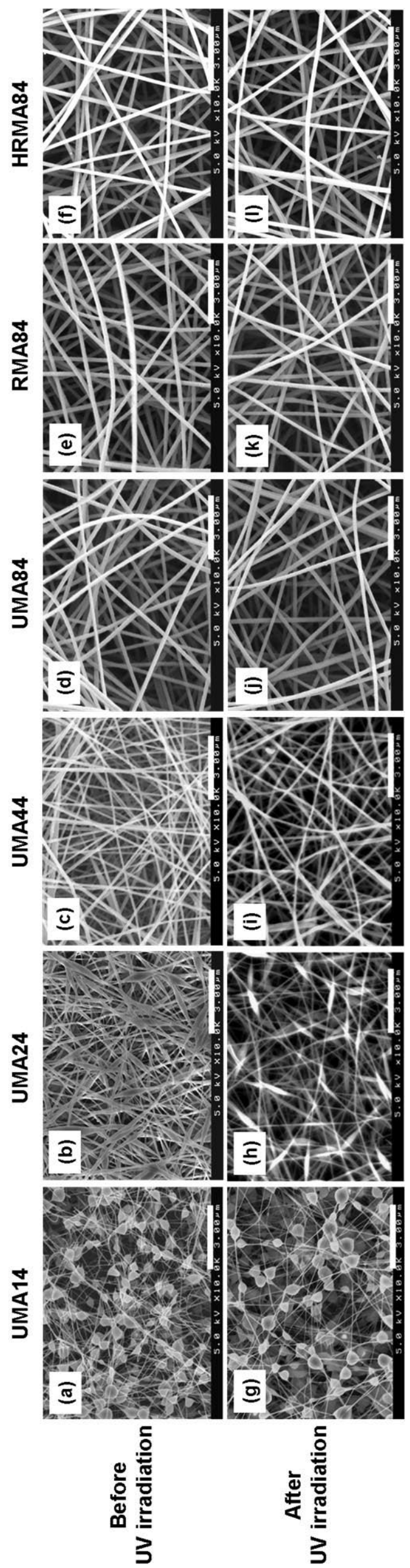

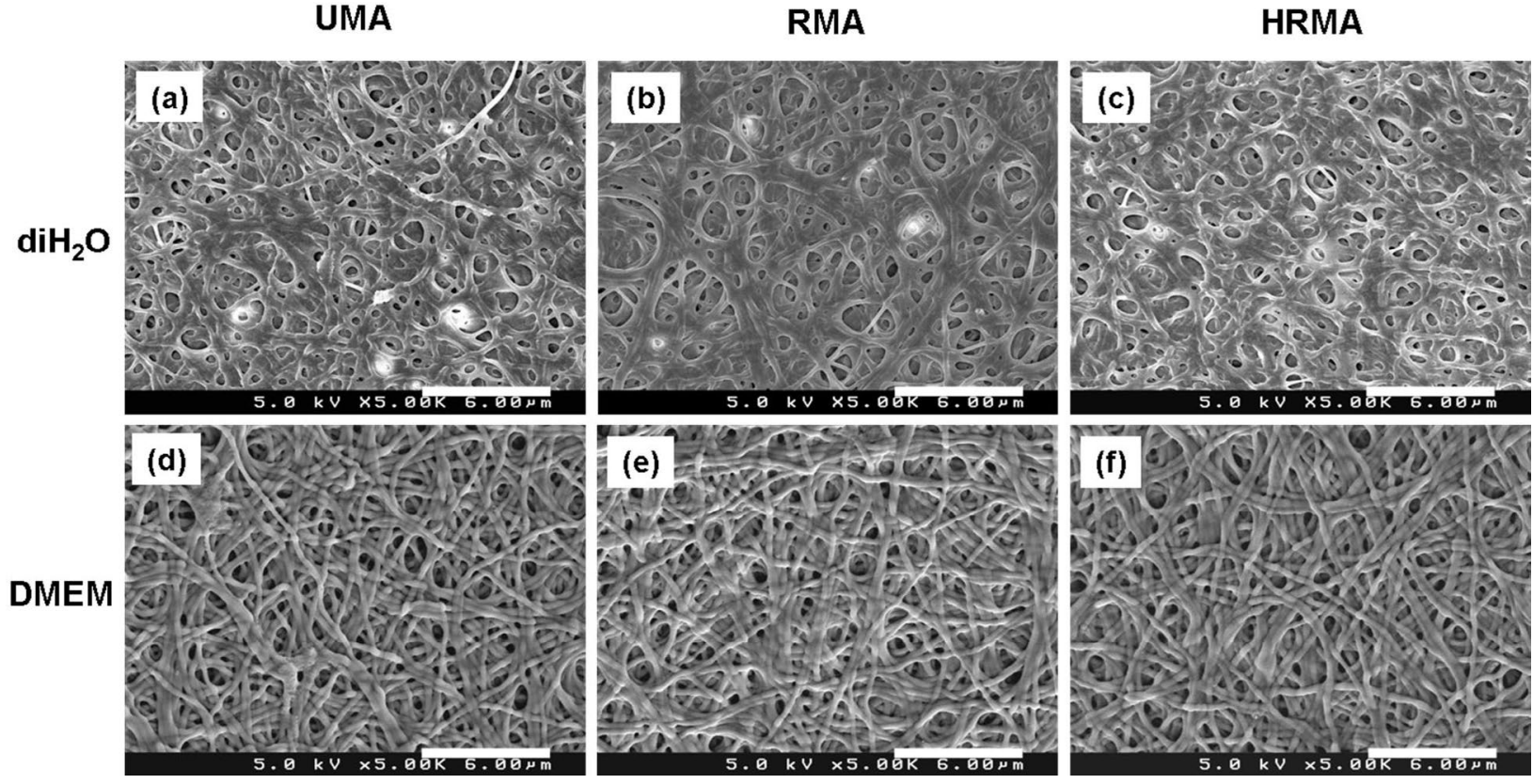

Fig. 4. Scanning electron micrographs of photo-cross-linked UMA84, RMA84, and HRMA84 nanofibres following PEO extraction in (a-c) $\mathrm{diH}_{2} \mathrm{O}$ and (d-f) DMEM at $37^{\circ} \mathrm{C}$ for 5 days. Images represent: (a and d) UMA84, (b and e) RMA84, and (c and f) HRMAP84. Scale bars represent $6 \mu \mathrm{m}$.

Table 2. The fibre diameters of electrospun UMA, RMA, and HRMA nanofibres (prior to PEO extraction) before and after UV irradiation, and photo-cross-linked UMA, RMA, and HRMA nanofibres following PEO extraction. Values are average \pm SD.

\begin{tabular}{|c|c|c|c|}
\hline Fibre diameters (nm) & Before cross-linking & After cross-linking & After PEO extraction \\
\hline UMA84 & $195.4 \pm 23$ & $183.2 \pm 27$ & $256.3 \pm 43$ \\
\hline RMA84 & $185.4 \pm 27$ & $190.4 \pm 30$ & $297.9 \pm 42$ \\
\hline HRMA84 & $185.5 \pm 37$ & $182.2 \pm 36$ & $278.2 \pm 40$ \\
\hline
\end{tabular}

$(50 \mathrm{mM} \mathrm{NaCl}, 150 \mathrm{mM}$ sucrose, $3 \mathrm{mM} \mathrm{MgCl}, 50 \mathrm{mM}$ Tris base, $0.5 \%$ Triton $\mathrm{X}-100)$ for $5 \mathrm{~min}$ at $4{ }^{\circ} \mathrm{C}$. The samples were incubated in blocking buffer $(1 \%$ bovine serum albumin (BSA), $0.1 \%$ Tween-20, $0.02 \%$ sodium azide in PBS) for $60 \mathrm{~min}$ at $37^{\circ} \mathrm{C}$. Following a wash in PBS, the samples were incubated for $60 \mathrm{~min}$ at $37^{\circ} \mathrm{C}$ in blocking buffer containing rhodamine-phalloidin at a 1:200 dilution (Invitrogen/Life Technologies, Carlsbad, CA, USA) to stain for F-actin microfilaments, and Hoechst 33258 at a 1:1000 dilution (Invitrogen/Life Technologies) to stain nuclear DNA. Following a gentle wash in PBS, samples were mounted in Fluoromount Aqueous Mounting Medium (Sigma-Aldrich) on glass slides. The samples were then visualised on a Nikon inverted fluorescence microscope (ECLIPSE TE 300, Nikon, Tokyo, Japan). Digital images were acquired using a digital camera (Retiga-SRV, QImaging, Burnaby, BC, Canada).

For quantification of changes in cell number after 1, 3 and 7 days of culturing, the samples were transferred to a new 12-well plate, and $1 \mathrm{~mL}$ of a $20 \%$ CellTiter 96 Aqueous One Solution (Promega, Madison, WI, USA) which contains 3-[4,5-dimethylthiazol-2-yl]-5[3-carboxymethoxy-phenyl]-2-[4-sulfophenyl]-2H- tetrazolium (MTS-tetrazolium) was added. The MTStetrazolium compound can be metabolised by mitochondria in living cells into a coloured formazan product that is soluble in cell culture medium. After incubating at $37^{\circ} \mathrm{C}$ for $90 \mathrm{~min}, 100 \mu \mathrm{L}$ of each solution was transferred to a 96-well plate and the absorbance at $490 \mathrm{~nm}$ was determined using a plate reader (SAFIRE, Tecan, Durham, NC, USA).

Growth factor release from the nanofibrous scaffolds The release of FGF-2 from the photo-crosslinked alginate nanofibrous scaffolds was determined. The photo-crosslinked, PEO-extracted, lyophilised scaffolds (diameter $20 \mathrm{~mm}, n=5$ ) were incubated with $100 \mathrm{ng}$ FGF-2 (for HRMA84 scaffolds) or 100 ng FGF-2 mixed with $2.5 \mu \mathrm{g}$ heparin (for UMA84 and RMA84 scaffolds) in PBS for $1 \mathrm{~h}$ at $4{ }^{\circ} \mathrm{C}$. When the growth factor solution was incubated with the nanofibrous scaffolds, the solution was completely absorbed into the scaffolds within $1 \mathrm{~h}$. The samples were then transferred to Transwell membranes (Corning, Corning, NY, USA) in 6-well tissue culture plates and incubated at $37^{\circ} \mathrm{C}$ in $5 \mathrm{~mL}$ DMEM for 14 days, with the media replaced at days $1,2,3,5,7,10$ and 14 . The amount of FGF-2 released into the media was determined 

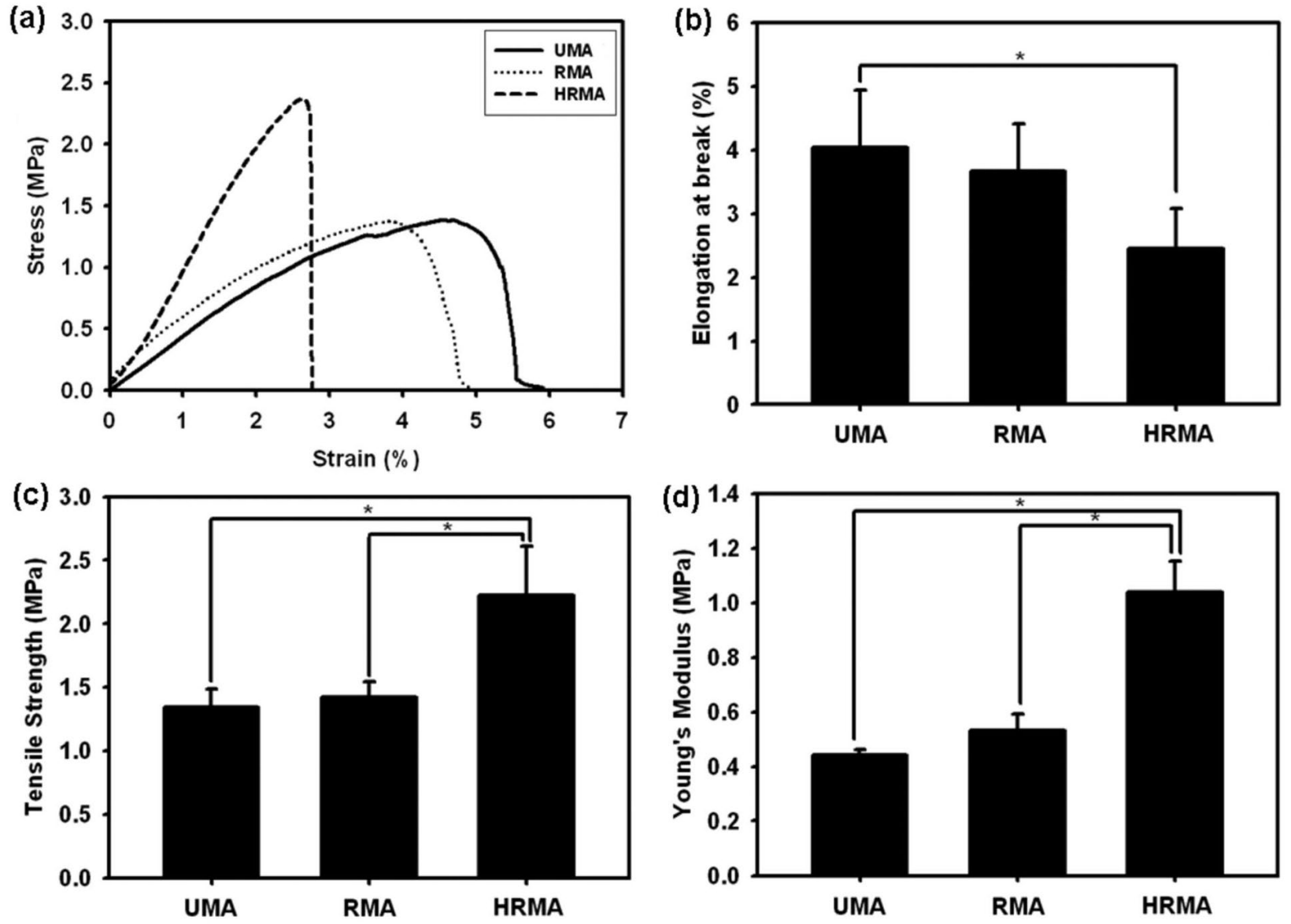

Fig. 5. (a) Representative stress-strain curves, (b) elongation at break, (c) tensile strength, and (d) Young's moduli of photo-cross-linked UMA84, RMA84, and HRMA84 nanofibres (prior to PEO extraction). * $p<0.05$

with an ELISA assay as per manufacturer's instructions (Duoset, R\&D Systems, Minneapolis, MN, USA).

To evaluate the activity of the encapsulated FGF-2 on cells, photo-crosslinked, PEO-extracted, lyophilised scaffolds $(n=5)$ were incubated with 100 ng FGF-2 (for HRMA84 scaffolds) or $100 \mathrm{ng}$ FGF-2 mixed with $2.5 \mu \mathrm{g}$ heparin (for UMA84 and RMA84 scaffolds) in PBS for $1 \mathrm{~h}$ at $4{ }^{\circ} \mathrm{C}$. These scaffolds were again placed in Transwell membranes in 6-well plates, with $1 \times 10^{4}$ HDFs seeded in the wells and cultured in $5 \mathrm{~mL}$ media as described above. A control population consisting of cells seeded in wells but cultured without scaffolds was examined. The change in cell number over time was measured indirectly using an MTS assay as previously described.

\section{Statistical analysis}

Data are expressed as mean \pm SD. Statistical analysis was carried out using ANOVA (InStat 3, GraphPad Software, La Jolla, CA, USA), and a value of $p<0.05$ was considered statistically significant.

\section{Results}

UMA, RMA, and HRMA were blended with PEO and electrospun to form nanofibrous scaffolds. The polymer solutions examined for electrospinning MA/
PEO nanofibres are listed in Table 1. To demonstrate that the photo-crosslinkable alginate could be electrospun, SEM photomicrographs of photo-crosslinked MA/ PEO nanofibres before and after crosslinking with UV irradiation for $10 \mathrm{~min}$ were obtained (Fig. 3). Before UV irradiation, some of the conditions (MA wt $\%$ of 1 or 2) resulted in nanofibres with beaded structures (Fig. 3a,b). Increasing the concentration of alginate to $4 \mathrm{wt} \%$ resulted in nanofibres with minimal beaded structures (Fig. 3c). Uniform nanofibres were obtained using UMA, RMA, and HRMA at $8.0 \mathrm{wt} \%$ of MA and $4.0 \mathrm{wt} \%$ PEO (Fig. 3d-f).

The electrospun crosslinked UMA, RMA, and HRMA scaffolds were soaked in $\mathrm{diH}_{2} \mathrm{O}$ or DMEM for 5 days to leach out the water-soluble and uncrosslinked PEO. After PEO extraction in $\operatorname{diH}_{2} \mathrm{O}$, the photo-crosslinked MA scaffolds lost their nanofibrous structure due to swelling (Fig. 4a-c). However, when the nanofibres were soaked in DMEM to extract the PEO, the scaffolds maintained a nanofibrous structure (Fig. 4d-f).

The average fibre diameters of MA scaffolds before and after photo-crosslinking were measured using the SEM images to determine if the crosslinking or heparin or RGD modification affected the fibre nanostructure (Table 2). There was a slight decrease in the fibre diameters of the scaffolds made with unmodified alginate after crosslinking, and no significant difference before and after crosslinking for the RMA or HRMA scaffolds. Others have also reported 
no change in the fibre diameters of photo-crosslinked nanofibres using UV irradiation (Jin et al., 2008). The fibre diameters increased upon extraction of the PEO in DMEM, due to some swelling of the nanofibres in the solution. However, these results indicate that the scaffolds maintain a nanofibrous structure even upon soaking in DMEM for 5 days.

Constant strain rate tensile tests were performed to determine the mechanical properties of the electrospun photo-crosslinked alginate nanofibre scaffolds before PEO extraction, specifically elongation at break, tensile strength and Young's modulus (Fig. 5). The addition of methacrylated heparin to the scaffolds was found to influence their mechanical properties as can be seen from representative stress-strain curves (Fig. 5a). The elongation at break for UMA and RMA was $4.04 \pm 0.90 \%$ and $3.67 \pm 0.75 \%$, respectively, and for HRMA it decreased even further to $2.46 \pm 0.62 \%$ (Fig. 5b); HRMA had a significantly lower elongation at break than UMA. The tensile strength and Young's modulus of HRMA (2.22 \pm 0.39 and $1.04 \pm 0.11 \mathrm{MPa}$, respectively) were significantly greater than UMA $(1.35 \pm 0.14$ and $0.44 \pm 0.02 \mathrm{MPa})$ and RMA scaffolds $(1.42 \pm 0.12$ and $0.53 \pm 0.06 \mathrm{MPa})$, indicating the heparin reinforced the nanofibres (Fig. 5c,d).

ATR-FTIR was used to examine the chemical composition of the nanofibres and verify the removal of PEO following 5 days extraction in media. The characteristic peaks for pure PEO were observed at 844 , 963, 1103 and $1343 \mathrm{~cm}^{-1}$ (Fig. 6a) (Ji et al., 2006). The carboxylic acid group of alginate was detected at 1616 $\mathrm{cm}^{-1}$ in pure alginate (Fig. 6b) and the photo-crosslinked alginate nanofibres before and after PEO extraction (Fig. 6c-f)(Lu et al., 2006). Note that the peaks characteristic of $\mathrm{PEO}$ are absent in the spectra for scaffolds that have been leached of PEO (Fig. 6d-f).

The stability and degradation of the nanofibres over time was studied by incubating the photo-crosslinked, PEO-extracted nanofibrous scaffolds in DMEM at $37^{\circ} \mathrm{C}$ for an additional 3 weeks beyond the 5 days required for PEO leaching, and then examining their morphologies with SEM. The scaffolds maintained their nanofibrous structure after 1 week of incubation (Fig. 7a-c), but lost this structure after 2 and 3 weeks of incubation (Fig. $7 \mathrm{~d}-\mathrm{i})$. To examine cellular interactions with the photocrosslinked, PEO-extracted scaffolds, HDFs were seeded and cultured on them for 7 days (Fig. 8). F-actin and nuclei staining of the cells at 1 and 7 days revealed that the few HDFs on UMA nanofibres remained rounded and did not proliferate substantially, while those on the RMA and HRMA nanofibres spread and proliferated (Figure 8a-f). The mitochondrial activity of the HDFs cultured on the nanofibre scaffolds was used as an indirect measure of changes in cell number over time, as assessed by an MTS assay (Fig. 8g).

It was hypothesised that the heparin modification of the photo-crosslinkable alginate would provide sustained release of heparin-binding growth factors from the electrospun nanofibres. Therefore, the release profiles of FGF-2 from photo-crosslinked, PEO-extracted UMA,
Fig. 6. ATR-FTIR spectra of electrospun nanofibres composed of photo-cross-linked alginate blended with PEO. (a) PEO alone, (b) pure alginate, (c) HRMA84 nanofibres, (d) PEO-extracted UMA84, (e) PEOextracted RMA84, (f) PEO-extracted HRMA84. White arrows indicate a characteristic peak of alginate; black arrows indicate $\mathrm{PEO}$ peaks.

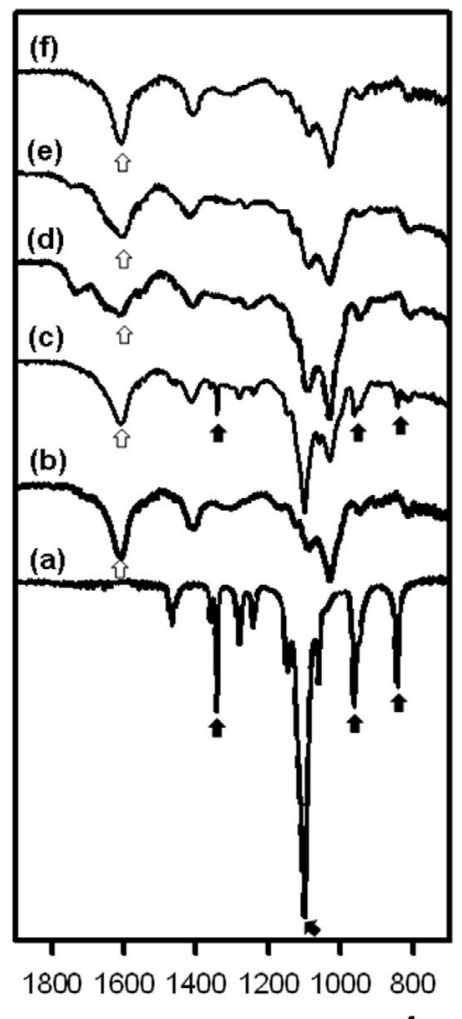

Wavenumber $\left(\mathrm{cm}^{-1}\right)$

RMA, and HRMA nanofibre scaffolds was examined (Fig. 9a). Indeed, it was shown that the release of this growth factor was more sustained from the nanofibres containing the heparin-modified alginate. FGF-2 has a mitogenic effect on cells (Chen et al., 2004), and thus the bioactivity of the released FGF-2 was examined by observing its effect on cell proliferation indirectly through MTS assay (Fig. 9b). Cells cultured with the UMA, RMA, and HRMA scaffolds for 1 and 4 days show similar levels of proliferation. At 7 days, there were significantly more cells cultured with the UMA and RMA scaffolds compared to those in media control without FGF-2, indicating that the bioactivity of the FGF-2 is preserved in these scaffolds. For the cells cultured with the HRMA scaffolds, by 4 days the cells showed significantly greater proliferation than those cultured in media, and by 7 days the cells cultured with the HRMA scaffolds exhibit a significantly higher degree of proliferation than those cultured with the UMA scaffolds or in media.

\section{Discussion}

Electrospinning can be used to form nanofibrous biopolymer scaffolds; these types of scaffolds have unique features including a high surface area to volume ratio and substantial interconnected pores. While alginate in its native form has been electrospun (Bhattarai et al., 2006; Lu et al., 2006; Jeong et al., 2010), electrospinning photopolymerisable alginate into stable nanofibres has not been demonstrated. Due to the benefits that photo-crosslinkable 
UMA

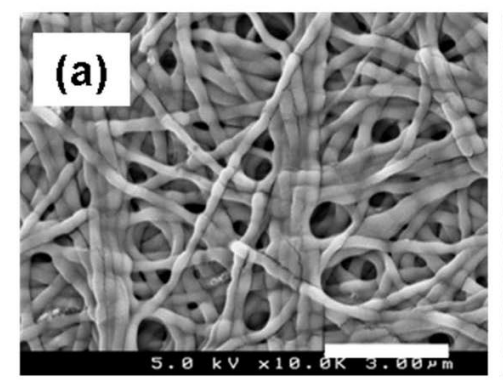

1 week

2 weeks
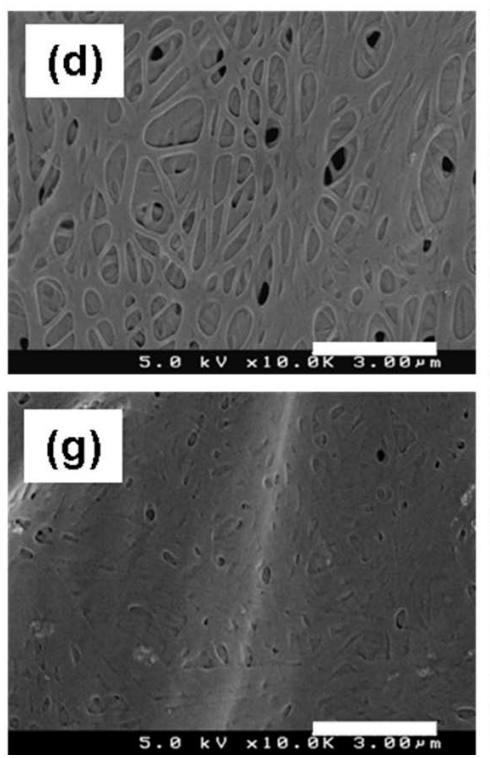

RMA
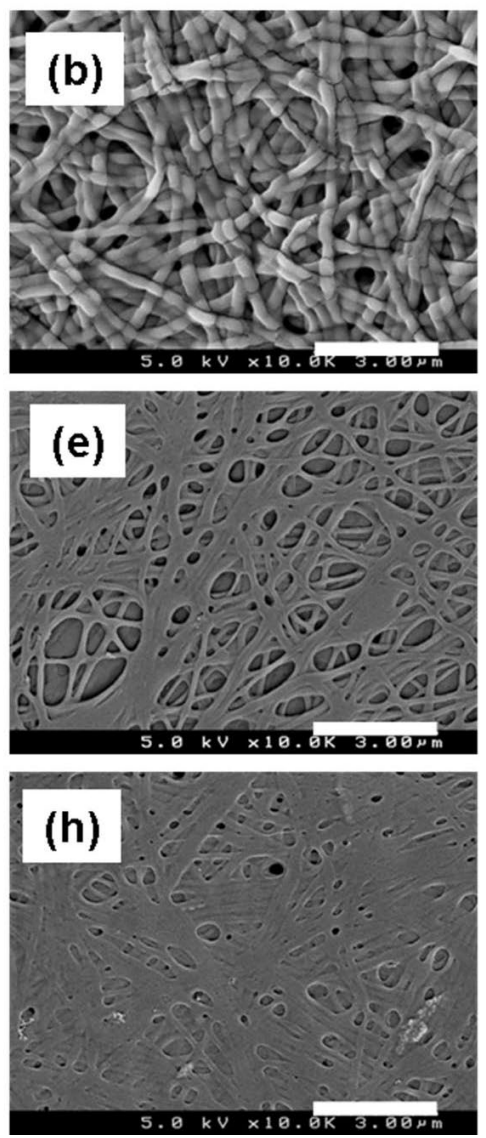

HRMA
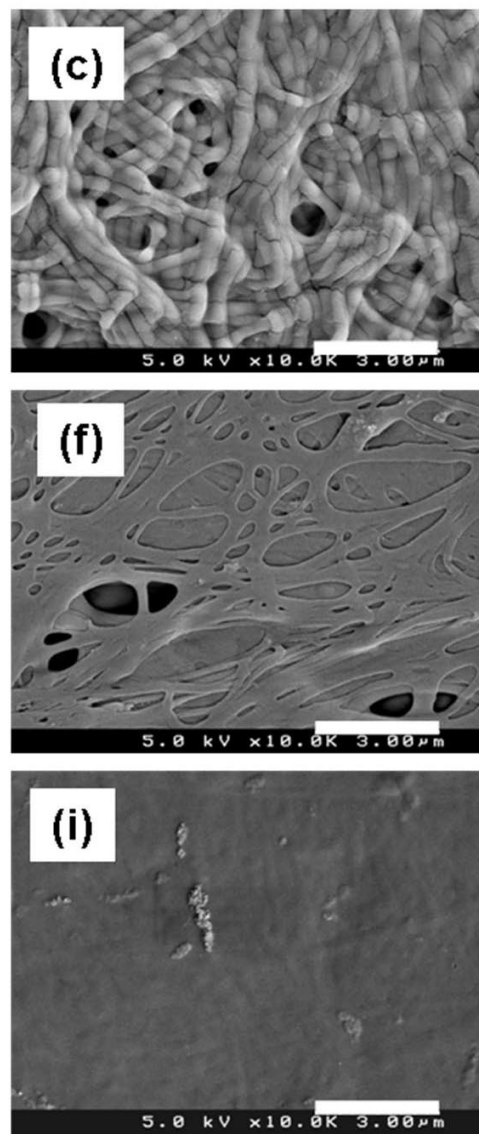

Fig. 7. The degradation of photo-cross-linked PEO-extracted UMA84, RMA84, and HRMA84 nanofibres incubated in DMEM at $37^{\circ} \mathrm{C}$ for (a-c) 1 week, (d-f) 2 weeks, and (g-i) 3 weeks. Scale bars represent $3 \mu \mathrm{m}$.

alginate can provide, including tailorable degradation, mechanical and cell adhesive properties and the ability to covalently incorporate methacrylated heparin into the crosslinked matrices for controlled protein delivery, it was important to ascertain whether this biomaterial could be electrospun into nanofibres and then photocrosslinked to maintain its nanofibrous structure. The goal of this work was threefold: (1) to demonstrate the capacity of methacrylated alginate to be electrospun into a nanofibrous matrix and subsequently photo-crosslinked, (2) to determine if cell adhesion and proliferation could be enhanced on these matrices by covalent modification with cell adhesion peptides, and (3) to incorporate heparin into the hydrogels during the photopolymerisation process to provide sustained release of bioactive heparin binding growth factors and examine their potential for accelerating cell proliferation on the matrices.

Alginate cannot be spun by itself, most likely because of a lack of chain entanglements (Nie et al., 2008). Therefore, it is typically electrospun in the presence of PEO or another biocompatible polymer, which when blended with alginate promotes the formation of uniform nanofibres during electrospinning (Jeong et al., 2010). Here, we have demonstrated that a blended solution of methacrylated alginate (which can be crosslinked by exposure to UV light) and PEO could be electrospun to form uniform nanofibres. The UV crosslinking and presence of RGD peptide or heparin had no visible effect on the morphologies of the nanofibres.

The mechanical properties of these nanofibres were measured by tensile testing. Interestingly, the presence of heparin in these scaffolds serves to change the mechanical properties, as evidenced by a statistically significant lower elongation at break (compared to the UMA scaffolds), higher tensile strength and higher Young's modulus (compared to both the UMA and RMA scaffolds). It is likely that the methacrylated heparin and PEO are interacting, possibly by hydrogen bonding between PEO and the carboxyl group of the heparin, in the nanofibres to provide these modified mechanical properties, as has been previously suggested for crosslinked networks of heparin and pluronic (Lee et al., 2010).

Although PEO was necessary for the electrospinning of the alginate, it is possible to have nanofibrous scaffolds comprised of alginate and/or alginate-heparin alone by leaching out the PEO; removing the inert PEO would provide cells a greater degree of contact with the biologically active modified polysaccharide. Therefore, using FTIR, it was demonstrated that the PEO could be successfully removed from these nanofibres to leave ALG 

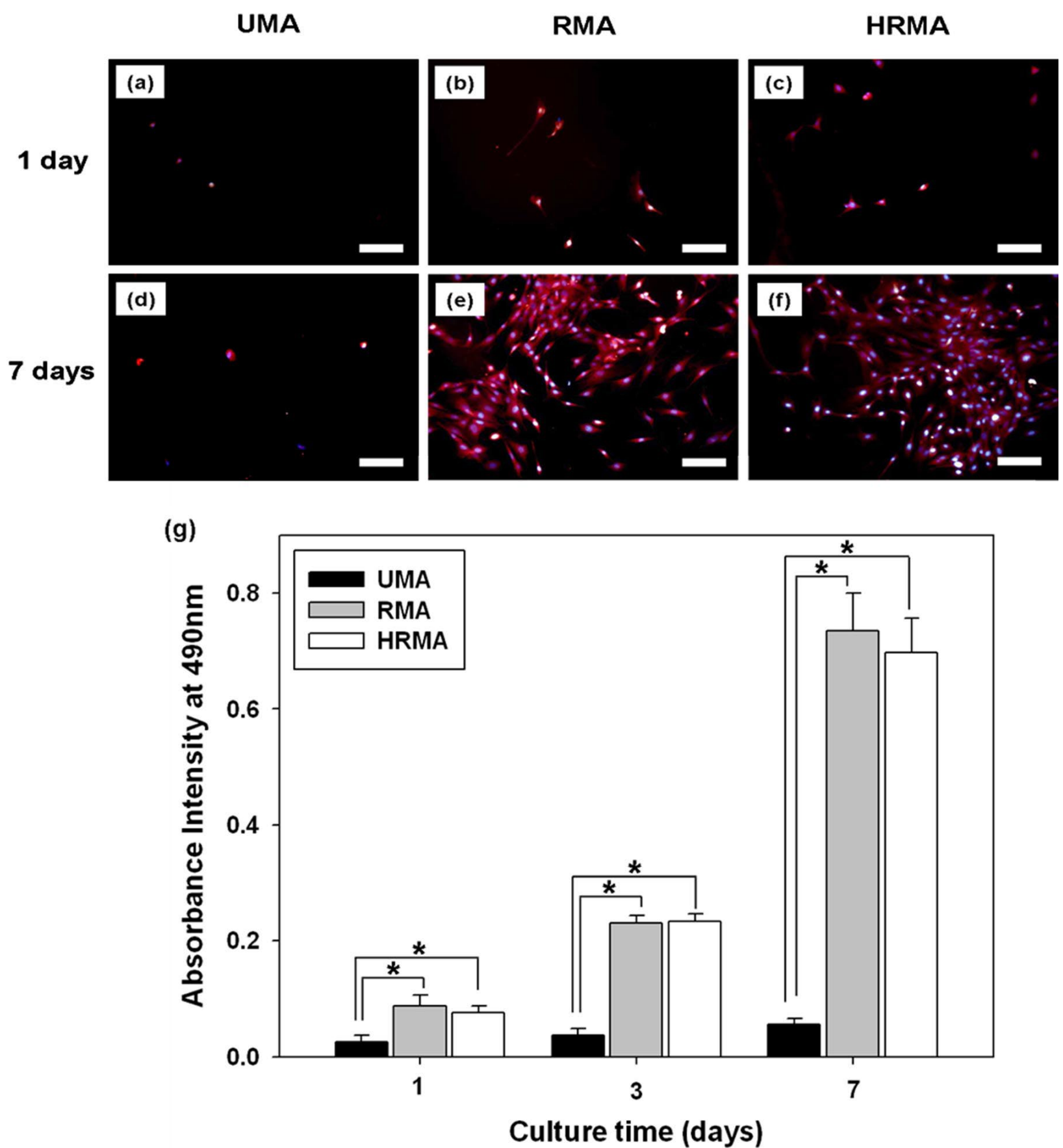

Fig. 8. (a-f) Fluorescence photomicrographs of HDFs cultured on photo-cross-linked PEO-extracted UMA84, RMA84, and HRMA84 nanofibre scaffolds stained with rhodamine-phalloidin and DAPI. Scale bars represent $100 \mu \mathrm{m}$. (g) MTS assay of HDFs cultured on these nanofibre scaffolds for 1,3 and 7 days. ${ }^{*} p<0.05$.

or HP-ALG nanofibres. In our previous report, photocrosslinked ALG and HP-ALG bulk hydrogels were stable in media for 8 weeks, but lost approximately $20 \%$ of their mass by 2 weeks (Jeon et al., 2011). However, the photocrosslinked alginate nanofibre scaffolds presented here degraded faster than bulk hydrogels. It is likely that the scaffolds degraded more rapidly due to the high surfaceto-volume ratio of the nanofibres, which would allow hydrolysis to occur on more of the scaffolds at earlier time-points compared to bulk hydrogels. Regardless, it is during this initial 1-2 weeks that increased surface-tovolume ratio of the material and therefore increased cell biomaterial interactions would likely have their maximal impact. For example, the presentation of adhesion ligands on the scaffold, such as the RGD-containing ligand in this study, to control cellular behaviour will provide the greatest influence at early time points prior to the cells secreting their own ECM. The scaffolds themselves are stable for at least 3 weeks, beyond the time point at which the nanoscale structure is lost.

The interconnected pores of a nanofibrous scaffold are important for cell infiltration and proliferation. Although the scaffolds soaked in $\mathrm{diH}_{2} \mathrm{O}$ swelled substantially and lost much of their porous nature, the photo-crosslinked 
(a)

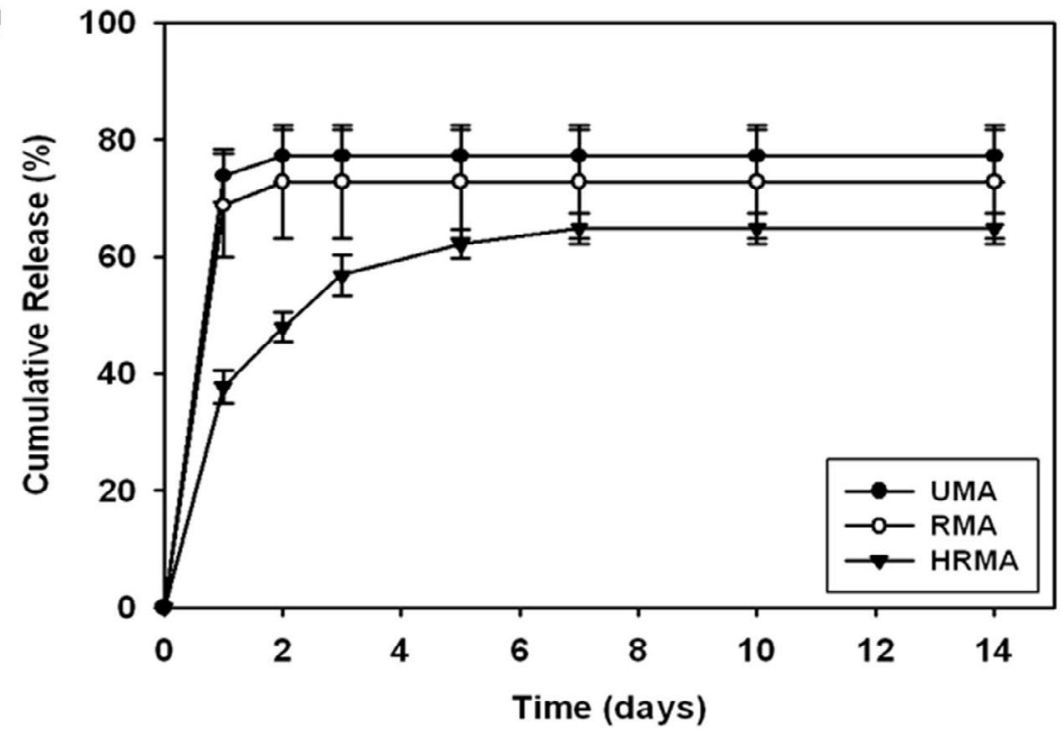

(b)

Fig. 9. (a) Cumulative release profiles of FGF-2 from photocross-linked, PEO-extracted UMA84, RMA84, and HRMA84 nanofibre scaffolds for 14 days and (b) MTS assay demonstrating the bioactivity of FGF-2 released from the photo-cross-linked, PEO-extracted UMA84, RMA84, and HRMA84 scaffolds. $* p<0.05$.

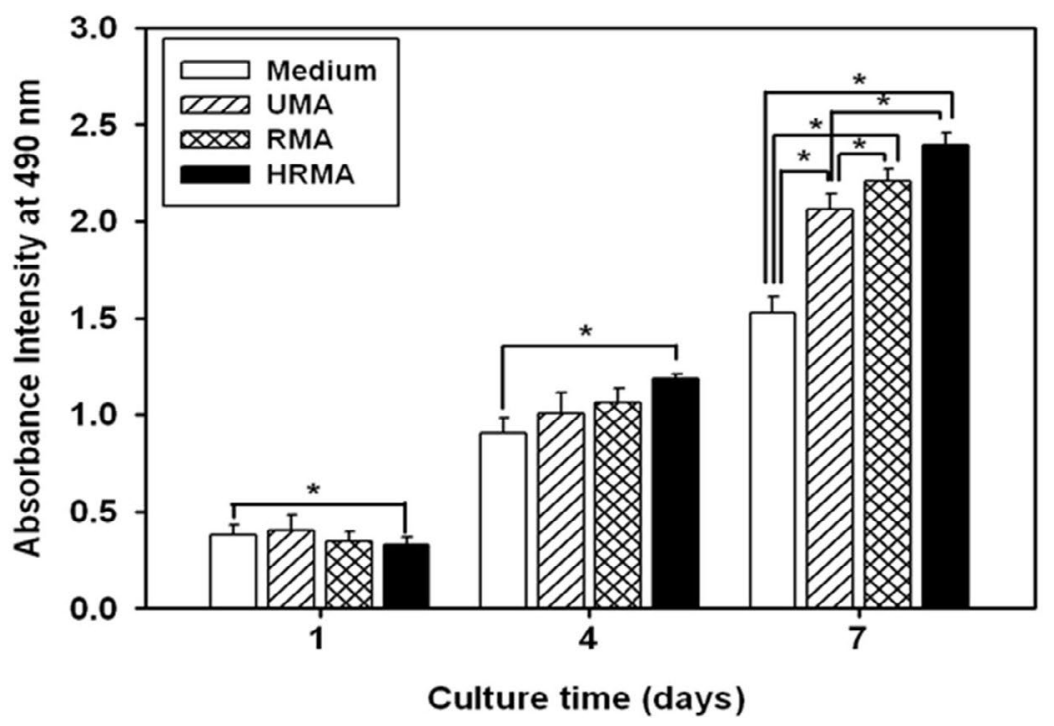

nanofibres soaked in DMEM have a porous structure (Fig. 4d-f) that may promote cell interactions with the scaffolds. The increased swelling of photo-crosslinked MA in $\mathrm{diH}_{2} \mathrm{O}$ compared to DMEM is likely osmosis driven, and has been reported in our previous work (Jeon et al., 2010). Although alginate is non-adhesive to cells, it can be chemically modified with cell adhesive peptide sequences to promote cell adhesion, migration, and proliferation in the scaffolds (Rowley et al., 1999). There were significantly more HDFs on the nanofibres modified with the cell adhesive peptide containing the RGD sequence compared to the unmodified alginate at all time-points, and the HDFs exhibited increased proliferation on the RGD-modified nanofibres. These findings demonstrate that the GRGDSP modification of the photo-crosslinkable alginate promotes cell adhesion, and in turn, proliferation.

Native ECM protects and sequesters growth factors (Benoit and Anseth, 2005; Schultz and Wysocki, 2009). The affinity of heparin and FGF-2 has been reported based on the electrostatic binding between the negatively charged sulphonyl and carboxyl groups of heparin and positively charged amino groups of FGF-2 (Raman et al., 2003; Schultz and Wysocki, 2009). Other groups have demonstrated release of FGF-2 from different heparinfunctionalised scaffolds (Benoit and Anseth, 2005; Guan et al., 2007; Sakiyama-Elbert and Hubbell, 2000; Shen et al., 2011; Wu et al., 2011). In this report, the release kinetics of FGF-2 from electrospun photo-crosslinked alginate fibres was quantified to determine if heparin could modulate FGF release and activity in this system. While the FGF-2 showed a burst release from the UMA and RMA nanofibres on the first day followed by little subsequent release, its release from the HRMA scaffolds was sustained over the course of one week. This indicates that the heparin in these scaffolds provides affinity binding of the growth factor, allowing it to remain within the scaffolds for a longer period of time before being released to the surrounding environment. Furthermore, the released FGF-2 was bioactive and capable of influencing cellular proliferation. Due to its sustained presentation to these cells, the growth factor released from the HRMA scaffolds enhanced the proliferation of the HDFs over time compared to that released from UMA or RMA scaffolds. These data demonstrate the importance that controlled and prolonged presentation of bioactive factors can have on regulating cell behaviour for tissue regeneration applications. 


\section{Conclusion}

In this study, photo-crosslinked alginate nanofibre scaffolds were prepared by electrospinning. The scaffolds were comprised of uniform nanofibres which crosslinked to form a porous structure. The photo-crosslinkable alginate could be modified with cell adhesive peptide sequences and/or with heparin to confer additional bioactivity to the scaffolds. The covalent coupling of a peptide containing the RGD cell adhesive sequence, which is found in fibronectin and other ECM molecules (Ruoslahti and Pierschbacher, 1987; Sechler et al., 1997), promoted the adhesion of HDFs to these nanofibrous scaffolds and subsequent proliferation over time; these are promising initial data for the use of this system in skin tissue engineering. It may be possible to tailor these scaffolds for use with other cell types for other applications through the use of other bioactive peptide sequences, for example sequences such as YIGSR or IKVAV, which are found in laminin (Graf et al., 1987; Tashiro et al., 1989). Additionally, it was demonstrated that by covalently modifying the alginate with heparin, FGF-2 was released in a sustained manner over the course of one week from these scaffolds, and the released growth factor retained its bioactivity as demonstrated by enhanced proliferation of HDFs. These scaffolds could also be used to achieve sustained release of different heparin-binding growth factors for other regenerative medicine pursuits. The release of heparin-binding growth factors might be further regulated by altering the concentration of heparin used in the scaffolds. In future studies, the degradation rate and mechanical properties of these nanofibres could be controlled by, for example, varying the degree of methacrylation, the molecular weight of the alginate, or by oxidising the alginate. In summary, these electrospun, biodegradable nanofibres composed of photo-crosslinkable alginate are promising for use as scaffolds in wound healing and tissue regeneration, as their physical (i.e., nanostructure, modulus and degradation rate) and cell adhesive properties and growth factor release profiles may be tailored for specific applications.

\section{Acknowledgements}

The authors gratefully acknowledge funding from the National Institutes of Health (AR063194, DE022376, AR061265), the AO Foundation, a Biomedical Research and Technology Transfer Grant 08-081 from the Ohio Department of Development, and a New Scholar in Aging grant from the Ellison Medical Foundation.

\section{References}

Andreopoulos FM, Persaud I (2006) Delivery of basic fibroblast growth factor (bFGF) from photoresponsive hydrogel scaffolds. Biomaterials 27: 2468-2476.

Barrientos S, Stojadinovic O, Golinko MS, Brem H, Tomic-Canic M (2008) Growth factors and cytokines in wound healing. Wound Repair Regen 16: 585-601.
Benoit DS, Anseth KS (2005) Heparin functionalized PEG gels that modulate protein adsorption for hMSC adhesion and differentiation. Acta Biomater 1: 461-470.

Bhattarai N, Li Z, Edmondson D, Zhang M (2006) Alginate-based nanofibrous scaffolds: Structural, mechanical, and biological properties. Adv Mater 18: 1463-1467.

Briganti E, Spiller D, Mirtelli C, Kull S, Counoupas C, Losi P, Senesi S, Di Stefano R, Soldani G (2010) A composite fibrin-based scaffold for controlled delivery of bioactive pro-angiogenetic growth factors. J Control Release 142: 14-21.

Casper CL, Yamaguchi N, Kiick KL, Rabolt JF (2005) Functionalizing electrospun fibers with biologically relevant macromolecules. Biomacromolecules 6: 19982007.

Chen CH, Poucher SM, Lu J, Henry PD (2004) Fibroblast growth factor 2: from laboratory evidence to clinical application. Curr Vasc Pharmacol 2: 33-43.

Freeman I, Kedem A, Cohen S (2008) The effect of sulfation of alginate hydrogels on the specific binding and controlled release of heparin-binding proteins. Biomaterials 29: 3260-3268.

Graf J, Ogle RC, Robey FA, Sasaki M, Martin GR, Yamada Y, Kleinman HK (1987) A pentapeptide from the laminin B1 chain mediates cell adhesion and binds the 67,000 laminin receptor. Biochemistry 26: 6896-6900.

Guan J, Stankus JJ, Wagner WR (2007) Biodegradable elastomeric scaffolds with basic fibroblast growth factor release. J Control Release 120: 70-78.

Ho YC, Mi FL, Sung HW, Kuo PL (2009) Heparinfunctionalized chitosan-alginate scaffolds for controlled release of growth factor. Int J Pharm 376: 69-75.

Janis JE, Kwon RK, Lalonde DH (2010) A practical guide to wound healing. Plast Reconstr Surg 125: 230e-244e.

Jeon O, Bouhadir KH, Mansour JM, Alsberg E (2009) Photocrosslinked alginate hydrogels with tunable biodegradation rates and mechanical properties. Biomaterials 30: 2724-2734.

Jeon O, Powell C, Ahmed SM, Alsberg E (2010) Biodegradable, photocrosslinked alginate hydrogels with independently tailorable physical properties and cell adhesivity. Tissue Eng Part A 16: 2915-2925.

Jeon O, Powell C, Solorio LD, Krebs MD, Alsberg E (2011) Affinity-based growth factor delivery using biodegradable, photocrosslinked heparin-alginate hydrogels. J Control Release 154: 258-266.

Jeong SI, Krebs MD, Bonino CA, Khan SA, Alsberg E (2010) Electrospun alginate nanofibers with controlled cell adhesion for tissue engineering. Macromol Biosci 10: 934-943.

Ji Y, Ghosh K, Zheng Shu X, Li B, Sokolov JC, Prestwich GD, Clark RAF, Rafailovich MH (2006) Electrospun three-dimensional hyaluronic acid nanofibrous scaffolds. Biomaterials 27: 3782-3792.

Jin Y, Yang DZ, Zhou YS, Ma GP, Nie J (2008) Photocrosslinked electrospun chitosan-based biocompatible nanofibers. J Appl Polymer Sci 109: 3337-3343. 
Lee SY, Tae G, Kim YH(2010) Accelerated micellization and aggregation of pluronic micelles by interaction with heparin. J Biomater Sci Polym Ed 21: 727-739.

Lu J, Zhu Y, Guo Z, Hu P, Yu J (2006) Electrospinning of sodium alginate with poly(ethylene oxide). Polymer 47: 8026-8031.

Macdonald ML, Rodriguez NM, Shah NJ, Hammond PT (2010) Characterization of tunable FGF-2 releasing polyelectrolyte multilayers. Biomacromolecules 11: 2053 2059.

Murugan R, Ramakrishna S (2006) Nano-featured scaffolds for tissue engineering: a review of spinning methodologies. Tissue Eng 12: 435-447.

Nillesen ST, Geutjes PJ, Wismans R, Schalkwijk J, Daamen WF, van Kuppevelt TH (2007) Increased angiogenesis and blood vessel maturation in acellular collagen-heparin scaffolds containing both FGF2 and VEGF. Biomaterials 28: 1123-1131.

Noh HK, Lee SW, Kim JM, Oh JE, Kim KH, Chung CP, Choi SC, Park WH, Min BM (2006) Electrospinning of chitin nanofibers: degradation behavior and cellular response to normal human keratinocytes and fibroblasts. Biomaterials 27: 3934-3944.

Park KM, Lee SY, Joung YK, Na JS, Lee MC, Park KD (2009) Thermosensitive chitosan-Pluronic hydrogel as an injectable cell delivery carrier for cartilage regeneration. Acta Biomaterialia 5: 1956-1965.

Perets A, Baruch Y, Weisbuch F, Shoshany G, Neufeld G, Cohen S (2003) Enhancing the vascularization of three-dimensional porous alginate scaffolds by incorporating controlled release basic fibroblast growth factor microspheres. J Biomed Mater Res A 65: 489-497.

Pham QP, Sharma U, Mikos AG (2006) Electrospinning of polymeric nanofibers for tissue engineering applications: a review. Tissue Eng 12: 1197-1211.

Powell HM, Boyce ST (2008) Fiber density of electrospun gelatin scaffolds regulates morphogenesis of dermal-epidermal skin substitutes. J Biomed Mater Res A 84: 1078-1086.

Powell HM, Supp DM, Boyce ST (2008) Influence of electrospun collagen on wound contraction of engineered skin substitutes. Biomaterials 29: 834-843.

Raman R, Venkataraman G, Ernst S, Sasisekharan V, Sasisekharan R (2003) Structural specificity of heparin binding in the fibroblast growth factor family of proteins. Proc Natl Acad Sci U S A 100: 2357-2362.

Robson MC (1997) The role of growth factors in the healing of chronic wounds. Wound Repair Regen 5: 12-17.

Rowley JA, Madlambayan G, Mooney DJ (1999) Alginate hydrogels as synthetic extracellular matrix materials. Biomaterials 20: 45-53.

Ruoslahti E, Pierschbacher MD (1987) New perspectives in cell adhesion: RGD and integrins. Science 238: 491-497.

Sahoo S, Ang LT, Goh JC, Toh SL (2010) Growth factor delivery through electrospun nanofibers in scaffolds for tissue engineering applications. J Biomed Mater Res A 93: $1539-1550$.

Sakiyama-Elbert SE, Hubbell JA (2000) Development of fibrin derivatives for controlled release of heparinbinding growth factors. J Control Release 65: 389-402.
Schultz GS, Wysocki A (2009) Interactions between extracellular matrix and growth factors in wound healing. Wound Repair Regen 17: 153-162.

Sechler JL, Corbett SA, Schwarzbauer JE (1997) Modulatory roles for integrin activation and the synergy site of fibronectin during matrix assembly. Mol Biol Cell 8: 2563-2573.

Shen H, Hu X, Yang F, Bei J, Wang S (2011) Cell affinity for bFGF immobilized heparin-containing poly(lactide-co-glycolide) scaffolds. Biomaterials 32: 3404-3412.

Tashiro K, Sephel GC, Weeks B, Sasaki M, Martin GR, Kleinman HK, Yamada Y (1989) A synthetic peptide containing the IKVAV sequence from the A chain of laminin mediates cell attachment, migration, and neurite outgrowth. J Biol Chem 264: 16174-16182.

Tigli RS, Akman AC, Gumusderelioglu M, Nohutcu $\mathrm{RM}$ (2009) In vitro release of dexamethasone or bFGF from chitosan/hydroxyapatite scaffolds. J Biomater Sci Polym Ed 20: 1899-1914.

Wongpanit P, Ueda H, Tabata Y, Rujiravanit R (2010) In vitro and in vivo release of basic fibroblast growth factor using a silk fibroin scaffold as delivery carrier. J Biomater Sci Polym Ed 21: 1403-1419.

Wu JM, Xu YY, Li ZH, Yuan XY, Wang PF, Zhang XZ, Liu YQ, Guan J, Guo Y, Li RX, Zhang H (2011) Heparinfunctionalized collagen matrices with controlled release of basic fibroblast growth factor. J Mater Sci Mater Med 22: 107-114.

Wu SC, Marston W, Armstrong DG (2010) Wound care: the role of advanced wound healing technologies. J Vasc Surg 52: 59S-66S.

Zahedi P, Rezaeian I, Ranaei-Siadat SO, Jafari SH, Supaphol P (2010) A review on wound dressings with an emphasis on electrospun nanofibrous polymeric bandages. Polym Advan Technol 21: 77-95.

Zhong SP, Zhang YZ, Lim CT (2010) Tissue scaffolds for skin wound healing and dermal reconstruction. Wiley Interdiscip Rev Nanomed Nanobiotechnol 2: 510-525.

\section{Discussion with Reviewer}

Reviewer II: The material is proposed as a scaffold for wound healing or regeneration of skin, but in fact all that has been done here is to grow some dermal fibroblasts on the surface. There is no indication that they produce any kind of extracellular matrix or go any further towards generating a new tissue than they would if they were grown in a plate. How do the authors propose to use this material to regenerate tissue, as opposed to just growing cells?

Authors: In order to regenerate wounded skin tissue, a dermal substitute must provide an environment that allows dermal fibroblasts to adhere, proliferate and deposit extracellular matrix just as they would in native tissue. As mentioned earlier, cells are not able to adhere to alginate naturally. With respect to investigating the influence of these nanofibres on regulating cellular behaviour, the first goal was to determine whether photo-polymerisable alginate could be electrospun into uniform nanofibres and 
then whether controlled RGD adhesion ligand presentation would enhance cell-biomaterial interactions with the nanofibre scaffolds. Following successful formation of stable nanofibres, human dermal fibroblasts were seeded on the surface of the scaffolds and cultured for seven days. Significantly greater cell adhesion and proliferation was quantified on the RGD-modified materials compared to the unmodified. The second goal of this manuscript was to determine if controlled delivery of FGF-2 from the scaffolds with or without adhesion peptide modification could enhance human dermal fibroblast proliferation. By day seven, all scaffolds releasing FGF-2 resulted in increased cell number compared to the control, and there was increased cell number in the heparin-modified scaffold condition compared to the unmodified scaffold condition. The ability to engineer these nanofibrous scaffolds to control cell adhesion and growth factor presentation, and thus influence cellular behaviours such as proliferation, demonstrates that indeed we are able to create a unique scaffold that can be tuned to regulate cellular function for the regeneration of specific tissues such as skin. In summary, we were able to successfully electrospin photocrosslinkable alginate into uniform nanofibres that offer controllable physical and biochemical properties and growth factor release capacity and thus may have great utility in wound healing. We recognise that this is a starting point for full development of a biomaterial technology that is capable of driving skin tissue regeneration, but this manuscript presents critical data demonstrating the potential of this new system for incorporation of specific physical and biochemical signals in a modular manner for regulating cell behaviour. 